Int. J. Dev. Biol. 59: 195-203 (2015)

doi: $10.1387 / \mathrm{ijdb} .140200 \mathrm{md}$

\title{
Down-regulation of msrb3 and destruction of normal auditory system development through hair cell apoptosis in zebrafish
}

\author{
XIAOFANG SHEN ${ }^{1, \#, ~ F E I ~ L I U ~}{ }^{1, \#,}$ YINGZHI WANG ${ }^{1}$, HUIJUN WANG ${ }^{2}$, JING MA $^{1}$, WENJUN XIA ${ }^{3}$, JIN ZHANG ${ }^{1}$, \\ NAN JIANG ${ }^{1}$, SHAOYANG SUN ${ }^{1}$, XU WANG $^{1}$ and DUAN MA ${ }^{*, 1,2,3}$ \\ ${ }^{1}$ Key Laboratory of Metabolism and Molecular Medicine, Ministry of Education, Department of Biochemistry and Molecular \\ Biology, Institute of Medical Sciences, School of Basic Medical Sciences, ${ }^{2}$ Children's Hospital of Fudan University and \\ ${ }^{3}$ Institute of Biomedical Science, School of Basic Medical Sciences, Fudan University, Shanghai, China
}

\begin{abstract}
Hearing defects can significantly influence quality of life for those who experience them. At this time, 177 deafness genes have been cloned, including 134 non-syndromic hearing-loss genes. The methionine sulfoxide reductase B3 (Ahmed et al., 2011) gene (also called DFNB74) is one such newly discovered hearing-loss gene. Within this gene c.265 T>G and c.55 T>C mutations are associated with autosomal recessive hearing loss. However, the biological role and mechanism underlying how it contributes to deafness is unclear. Thus, to better understand this mutation, we designed splicing morpholinos for the purpose of down-regulating msrb3 in zebrafish. Morphants exhibited small, tiny, fused, or misplaced otoliths and abnormal numbers of otoliths. Down-regulation of $\boldsymbol{m s r b 3}$ also caused shorter, thinner, and more crowded cilia. Furthermore, L1-8 neuromasts were reduced and disordered in the lateral line system; hair cells in each neuromast underwent apoptosis. Co-injection with human MSRB3 mRNA partially rescued auditory system defects, but mutant MSRB3 mRNA could not. Thus, msrb3 is instrumental for auditory system development in zebrafish and MSRB3-related deafness may be caused by promotion of hair cell apoptosis.
\end{abstract}

KEY WORDS: deafness, zebrafish, otolith, hair cell, neuromast

\section{Introduction}

Hearing loss is a common but significant birth defect that conveys sensorineural disability (Hilgert et al., 2009) and approximately one of every 1,000 infants has some form of congenital hearing loss (Blanchard et al., 2012). Also, an estimated 28 million Americans, 27.8 million Chinese, and 22.5 million Europeans suffer from hearing defects (Cheng et al., 2011). Sensorineural hearing loss may originate in the organ of Corti within the inner ear (Usami et al., 1998, Kelley, 2007). Sound waves are transferred to the middle ear, vibrating the tympanic membrane, and then ossicles amplify the sound energy and transmit it to the fluid-filled cochlea. Eventually, these movements are converted into fluctuations in the basilar membrane and then into changes in the relative positions of stereocilia and tectorial membranes, stimulating hair cells. Then, hair cells convert this mechanical energy into electrical signals. The organ of Corti is composed of hair cells, supporting cells, and stereocilia, and a slight damage to this organ can cause serious hearing impairment (Borck et al., 2011, Dror and Avraham, 2010, Gillespie and Muller, 2009, Frolenkov et al., 2004). Hair cells, supporting cells, stereocilia, and otoliths in zebrafish have functions similar to their human counterparts. Furthermore, research suggests that the necessary genes for normal hearing account for nearly $1 \%$ of all human genes (Friedman and Griffith, 2003). At this time, 177 deafness genes have been cloned (http://hereditaryhearingloss. org/main. aspx?c=.HHH\&n=86307), which is a substantial advance in deafness research, but the pathogenic mechanisms underlying how these deafness genes (such as MSRB3) cause hearing loss are not understood.

Researchers have identified methionine sulfoxide reductase B3 (MSRB3) as a deafness gene via sequencing the genes of affected

Abbreviations used in this paper: MSRB3, methionine sulfoxide reductase B3.

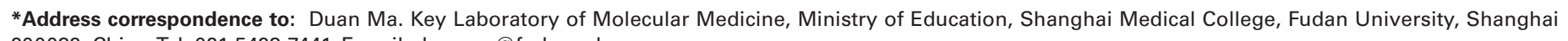
200032, China.Tel: 021-5423-7441. E-mail: duanma@fudan.edu.cn

\#Note: The indicated authors contributed equally to this work.

Accepted: 28 May 2015.

ISSN: Online 1696-3547, Print 0214-6282 
individuals. This gene can repair proteins damaged by oxidative stress by catalyzing methionine sulfoxides, reducing them to their corresponding methionines (Weissbach et al., 2002). MSRB3 has four transcripts encoding two isoforms (MSRB3A and MSRB3B). MSRB3A is predicted to exist in the endoplasmic reticulum, and MSRB3B may be within the mitochondria. Two homozygous mutations, c.265T>G and $\mathrm{c} .55 \mathrm{~T}>\mathrm{C}$, were reported to be deafness mutations of MSRB3 (Ahmed et al., 2011). The c. $265 \mathrm{~T}>\mathrm{G}$ mutation can lead to loss of activity of MSRB3A, and the c. $55 \mathrm{~T}>$ $\mathrm{C}$ mutation is a truncating mutation. Thus, these data suggest that functional MSRB3 is critical to human hearing. In an attempt to better understand the pathogenesis of DFNB74 deafness caused by MSRB3 deficiency, Kwon's group generated Msrb3 knockout mice using homologous recombination and reported that Msrb3 deficiency caused progressive degeneration of stereocilia, followed by hair cell apoptosis and that this caused profound deafness in Msrb3- $^{--}$animals (Kwon et al., 2014).

Zebrafish do not have an outer or middle ear, but instead have a typical vertebrate inner ear, which has been previously described (Whitfield, 2002, Waterman and Bell, 1984, Haddon and Lewis, 1996, Bang et al., 2001, Bever and Fekete, 2002). Also, zebrafish have a lateral line system of neuromasts containing hair cells whose stereocilia are directly exposed to the water, sensing movement along the head and body surface. Unlike inner ear hair cells, neuromasts are present on the animal surface, making them highly accessible and easy to study (Ma et al., 2008, Nagiel et al., 2008, He et al., 2013). Finally, msrb3homology between Homo sapiens and D. rerio is as high as $84.87 \%$, which confirms that zebrafish are a suitable animal model for studying vertebrate ear development and function (Wu et al., 2010, Whitfield, 2002). Here, we describe Msrb3 knockout zebrafish, which we used to investigate how DFNB74 contributes to deafness caused by the loss of MSRB3.

\section{Results}

\section{Two kinds of morpholinos can knock down the expression of msrb3}

Whole-mount in situ hybridization (WISH) at 12 and 26 hours post fertilization (hpf) revealed that $m s r b 3$ was widely expressed in embryos, especially in the inner ear (Fig. 1A). To understand how msrb3 works, two splice morpholinos were designed to downregulate normal msrb3 expression in zebrafish. Binding of these two morpholinos at their respective binding sites caused retention of intron2 and loss of exon2 (Fig. 1B). After microinjection, the efficiency of In2MO and Ex2MO was measured with RT-PCR. Primers designed to measure In2MO efficiency were expected to produce a 179 bp product in control embryos (In2Con), and morphants were expected to produce a 299 bp product (In2MO) (Fig. 1C). Primers designed to confirm the efficiency of Ex2MO should yield morphants (Ex2MO) without the 163 bp product found in control embryos (Ex2Con) (Fig. 1D). RT-PCR showed that the expression of msrb3 was largely down-regulated (Fig. 1E).

\section{Decreased msrb3 caused otic developmental defects}

Tolearn whether msrb3is essential to zebrafish otic development,
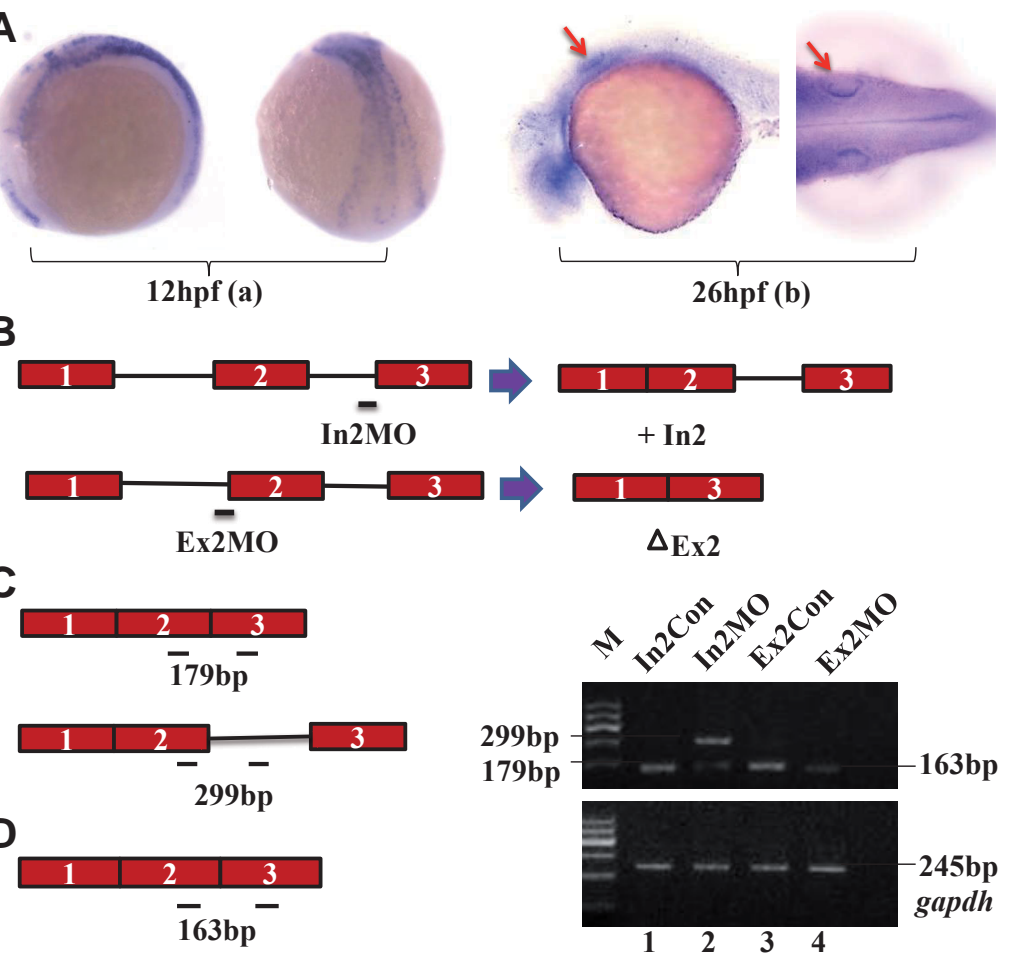

Fig. 1. Efficiency of $\mathbf{m s r b 3}$ morpholinos. (A) WISH at 12 hpf showed that msrb3 was widely expressed in embryos (a). At 26 hpf msrb3 was highly expressed in the inner ar of embryos (b). (B) Morpholino antisense oligonucleotides. (C) Primers designed o measure efficiency of In2MO (179 bp and 299 bp products). (D) Primers designed to measure efficiency of Ex2MO (less 163 bp product). (E) Morpholino efficiency: wo msrb3 morpholinos could interfere with normal mRNA splicing (compare lane to lane 2 and lane 3 to lane 4).

morphant phenotypes were observed and compared to controls. First, morphology of controls (Fig. 2A a,c) and msrb3 morphants (Fig. 2A b,d) were observed at $60 \mathrm{hpf}$, and msrb3 morphants had otolith abnormalities. Otic vesicles visualized with DIC microscopy revealed that by $60 \mathrm{hpf}$, two otoliths appeared in control embryos (Fig. $2 \mathrm{~A} \mathrm{e}, \mathrm{k}$ ) and the otolith closer to the eyes was smaller. However, msrb3 morphants exhibited tiny (Fig. 2A f,I), fused (Fig.2A h,n), misplaced (Fig. 2AI,o), or small (Fig. 2Aj,p) otoliths, abnormal otolith numbers (Fig. 2A g,m), and malformed semicircular canals (Fig. 2A f-g, I-p). A quantitative analysis of otolith defects of both morphants was performed at $60 \mathrm{hpf}$. Fish with the defect are depicted in Fig. 2 B,C. Each experiment was performed in triplicate and otolith abnormalities in controls and msrb3 morphants were statistically significantly different (Fig. 2 D,E).

\section{Msrb3 is essential for the development of cilia in inner ear and lateral line neuromasts}

Inner ear sterecilia of $5 \mathrm{dpf}$ zebrafish were marked with FITClabelled phalloidin and observed under confocal microscopy. Msrb3 morphants (Fig. 3 B,D) had semicircular canal defects not present in controls (Fig. 3 A,C). Sterecilia of msrb3 morphants (Fig. 3 B,D) were shorter and more crowded than controls. Kinocilia in lateral line neuromasts were observed under SEM and these were shorter in morphants (Fig. 3 E-H). Statistical analysis of inner ear sterecilia (Fig.3I) and neuromasts kinocilia(Fig.3J) in mismatch controls and msrb3 morphants indicated statistical significance. 


\section{Decreased msrb3 caused disordered neuromasts and fewer hair cells}

Zebrafish have a special lateral line system composed of neuromasts containing hair and supporting cells (Ghysen, 2003). We labeled hair cells with a transgenic fish: Tg (Brn3c:mGFP) S356T transgenic zebrafish expressing GFP in hair cells under control of the POU4F3 promoter that is targeted to the plasma membrane with a GFP-43 membrane targeting sequence. Hair cells in neuromasts were visualized by allowing embryonic zebrafish to swim in FM-1-43FX (red) dye which binds to nerve cell membranes via a mechanotransduction channel (Gleason et al., 2009). Then larvae were fixed in $4 \%$ paraformaldehyde and nuclei were labeled with DAPI (blue) to visualize neuromasts and hair cells. Down-regulation of msrb3 produced fewer and disordered lateral line neuromasts (Fig. 4 A,B) and fewer neuromast hair cells (Fig. 4 D,E). Statistical analysis of L1-8 neuromasts (Fig. 4C) and hair cells per neuromast (Fig. 4F) in mismatch controls and msrb3 morphants were significantly different.

\section{Msrb3 deficiency leads to apoptotic hair cell death in neuromasts}

A TUNEL assay was performed with a TMR-RED in situ cell death detection kit. Results showed significantly more apoptotic hair cells in neuromasts of $3 \mathrm{dpf}$ morphants than in those of controls (Fig. 5 A,B). Statistical analysis of apoptotic hair cells per neuromast in mismatch controls and msrb3 morphants indicated statistical significance (Fig. 5C)

Technologies used to study gene function sy sequence-specific knockdown can elicit undesirable off-target effects. About $15-20 \%$ of morpholinos used in zebrafish have off-targeted effects (Ekker and Larson, 2001). Although not all underlying causes of off-target effects were clear, most of these were mediated via $p 53$ activation which is well described (Robu et al., 2007, Gerety and Wilkinson, 2011). To rule out the possibility of whole-body apoptosis mediated by $p 53$,
A
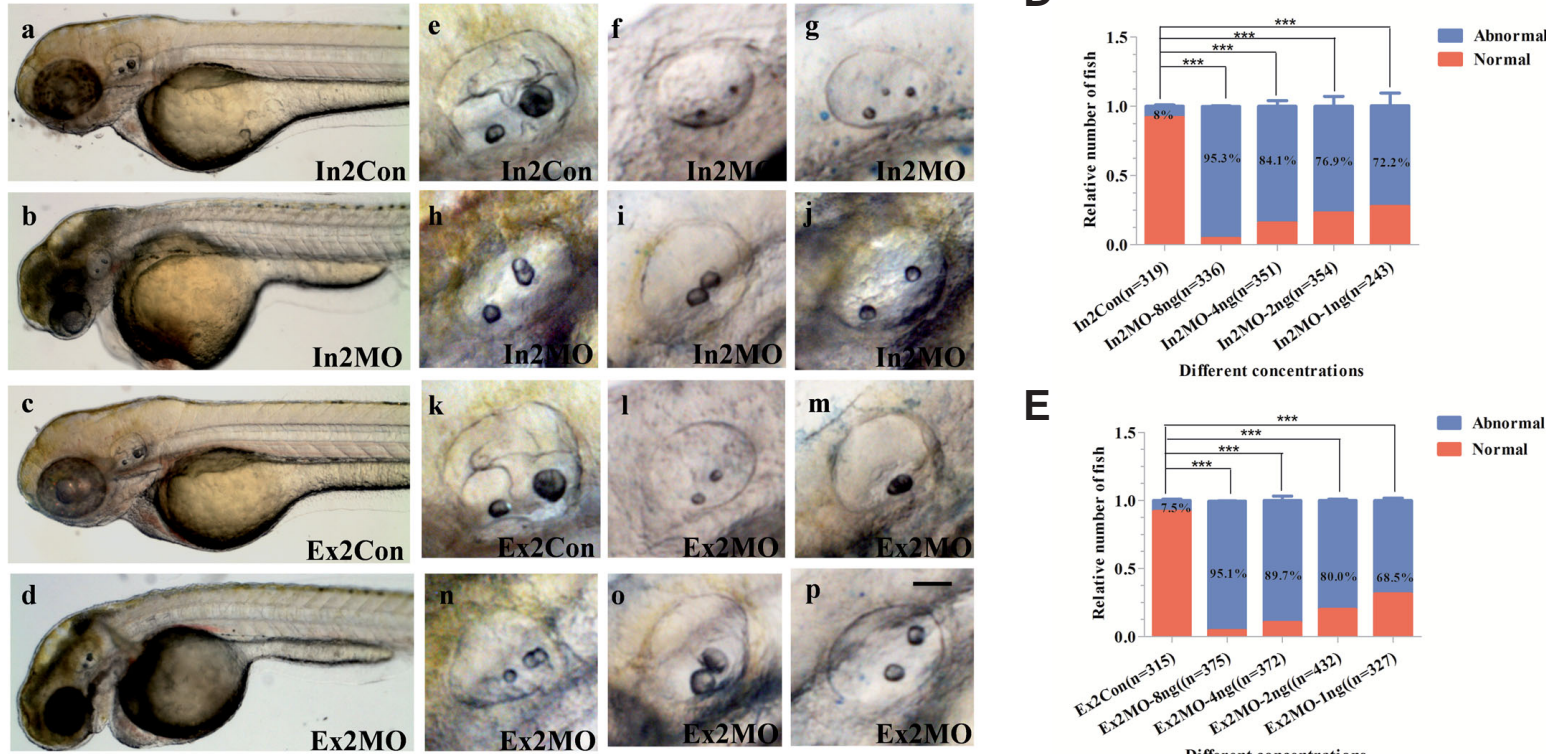

\section{E}

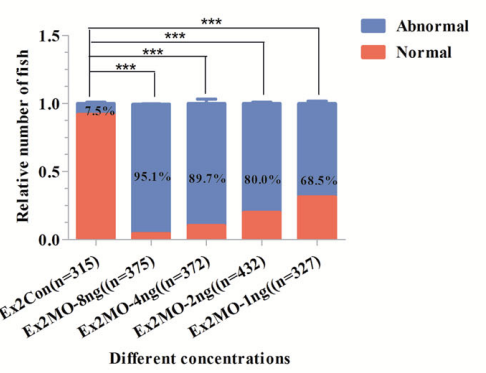

C

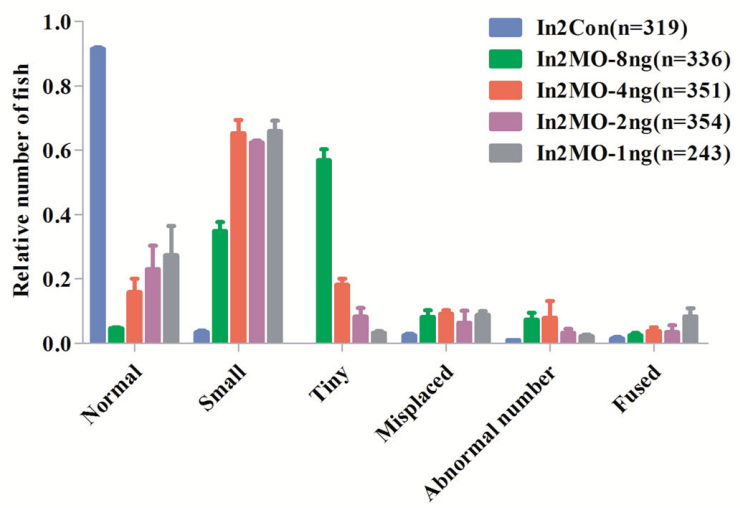

Type of otoliths

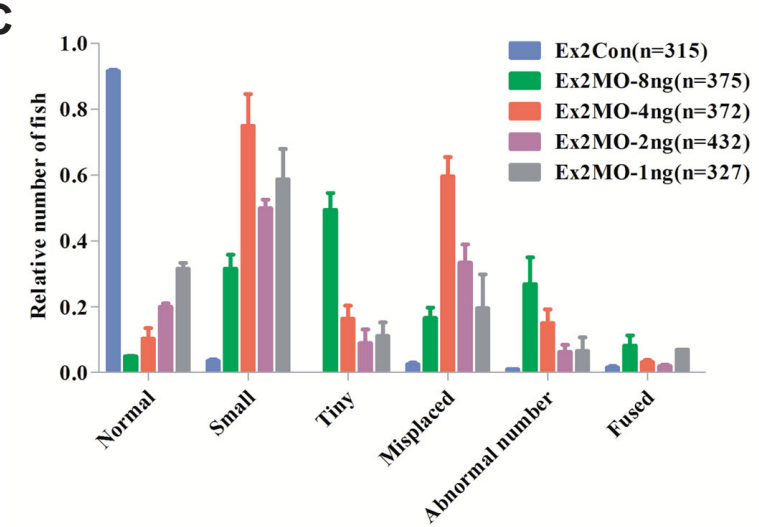

Type of otoliths

Fig. 2. Otic developmental defects in Msrb3 morphants. (A) Overall morphology of mismatched controls (In2Con, a; Ex2Con, c) and msrb3 morphants (In2MO, b; Ex2MO, d) at 60 hpf indicated otolith abnormalities. Otic vesicles were visualized at 60 hpf using DIC microscopy. Scale bars: 50 um. Unlike mismatch control (e; $k)$, msrb3 morphants had tiny otoliths (f, I), abnormal otolith numbers $(g, m)$, fused otoliths (h, $n)$, misplaced otoliths (i, o), small otoliths (j, p), shrunken inner ears, and malformed semicircular canals ( $f-g, l-p)$. (B,C) Quantitative analysis of otolith defects of In2MO and Ex2MO at different concentrations at 60 hpf. Relative number of fish with otic developmental defects. (D,E) Statistical analysis of otolith abnormalities in controls and msrb3 morphants. Error bars are s.d. ${ }^{* *} \mathrm{*}<0.0001$. 
larvae were injected with msrb3 morpholinos (In2MO, Ex2MO) or co-injected with msrb3 morpholinos and p53MO. Acridine orange staining was used to detect whole apoptosis signals of larvae at $24 \mathrm{hpf}$. There were no obvious differences in apoptotic signals between whole msrb3 morphants and p53MO co-injected larvae (Fig. 5 D,E). Thus, the morpholino off-target effect was ruled out.

\section{Human MSRB3A mRNA can rescue otic defects in msrb3 morphants}

Down-regulation of msrb3 caused otic developmental defects in zebrafish. This gene shares $68.28 \%$ homology with human msrb3 (Fig. 6A). Therefore, human MSRB3A and MSRB3A265T > G were obtained (Fig. 6B) and transcribed into mRNA and human MSRB3A mRNA or MSRB3A-265T>GmRNA was injected into zebrafish embryos with morpholinos to determine whether MSRB3A mRNA from humans could rescue defects caused by

A

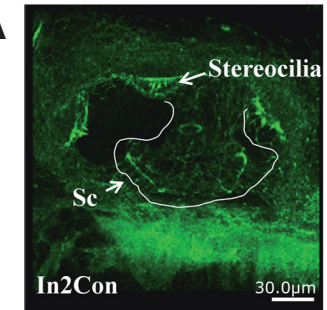

B

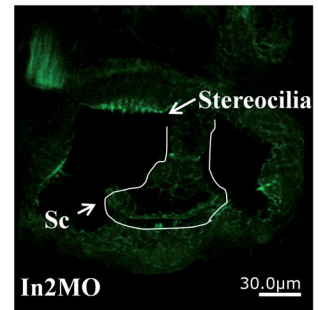

C

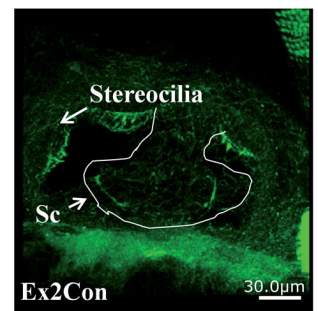

D

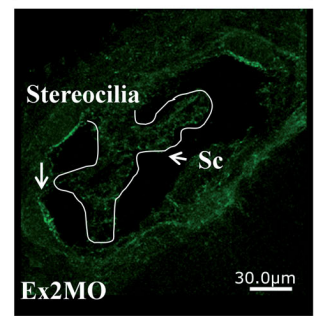

I

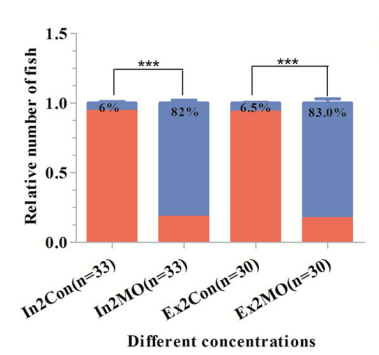

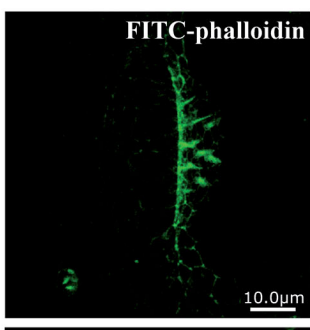
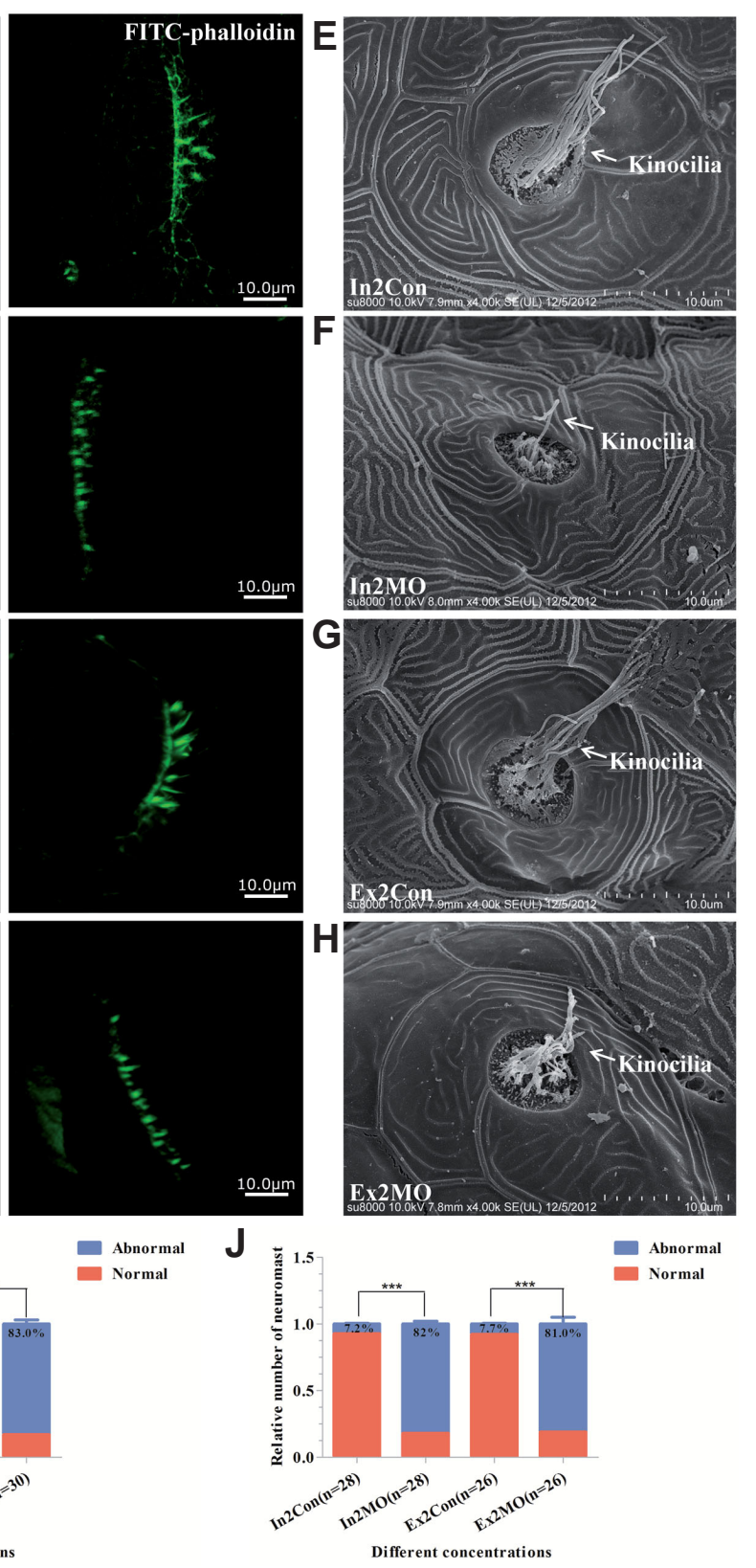

reduced msrb3 expression. Results show that human MSRB3A mRNA but not the mutant MSRB3A mRNA could significantly rescue otic defects of zebrafish morphants (Fig. 6 C,D). Finally, controls and different msrb3 morphants were significantly different (Fig. 6 E,F).

\section{Msrb3 morphants at 6 dpf had hearing loss}

The inner ear is critical for crucial roles in zebrafish hearing and balance. After inducing inner ear defects in msrb3morphants, swimming and hearing were investigated and we observed that larvae injected with control morpholinos usually swam or rested with their backs facing up and swam at a consistent depth. However, msrb3 morphants remained stationary and rested in abnormal positions, swimming up and down or in circles. The abnormal swimming behavior of msrb3 morphants indicated a defective balance system.

To confirm hearing impairment, the C-shaped startle response was also tested using near-field pure tone stimulation with sound intensity $(500 \mathrm{~Hz}$, $80 \mathrm{~dB}$ ). The $\mathrm{C}$-startle response of morphants took longer to manifest than control larvae, especially those with very small otoliths. Some morphants had no response to voice stimulation. After co-injection with human MSRB3AmRNA ( $h M 3 A)$, about half of the morphants regained some hearing (Fig. $7 \mathrm{~B}, \mathrm{D}$ ). Morphant swimming postures tended to normalize, and audio stimulus sensitivity was greatly increased (Fig. 7 A,C). These findings support the idea that msrb3 is key to zebrafish hearing.

\section{Discussion}

Hair cells, supporting cells, and cilia are so important that even slight damage can cause serious hearing impairment in both humans and zebrafish (Dror and Avraham, 2010, Gillespie and Muller, 2009, Frolenkov et al., 2004, Borck et al., 2011). Morphogenesis of zebrafish otic vesicles has been described in detail (Kimmel et al., 1995, Haddon and Lewis, 1996) and in this depiction, the zebrafish embryonic inner ear appears as a solid otic placode near the hindbrain by $13.5 \mathrm{hpf}$. Then the placode hollows out into the otic vesicle at 18.5 hpf. Precursor dispersal particles in otic vesicles are attracted by vortices caused by stereocilia

Fig. 3. Cilia damage in Msrb3 morphants. (A-D) Stereocilia in zebrafish inner ear marked with FITC-labeled phalloidin (confocal microscopy). Stereocilia in msrb3 morphants (In2MO, Ex2MO) were shorter and thinner than those of mismatch controls (In2Con, Ex2Con). In addition, msrb3 morphants had malformed semicircular canals. Scale bars: 30 um. (E-H) Kinocilia in lateral line neuromasts of morphants were damaged (not see in controls). Scale bars: $10 \mu \mathrm{m}$. (I) Statistical analysis of inner ear stereocilia in controls and msrb3 morphants, " $n$ " represents fish number. Error bars are s.d. ** $\mathrm{*}<0.0001$. (J) Statisticalanalysis of neuromast kinocilia in controls and msrb3 morphants, " $n$ " represents neuromasts number. Error bars are s.d. ${ }^{* *} \mathrm{P}<0.0001$. 
A

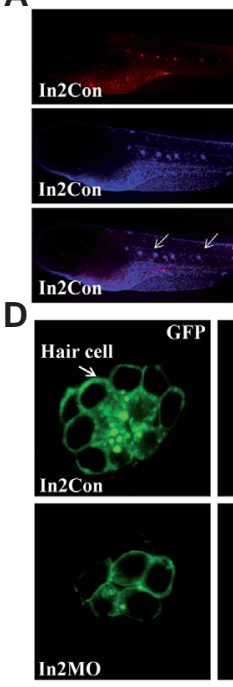

B

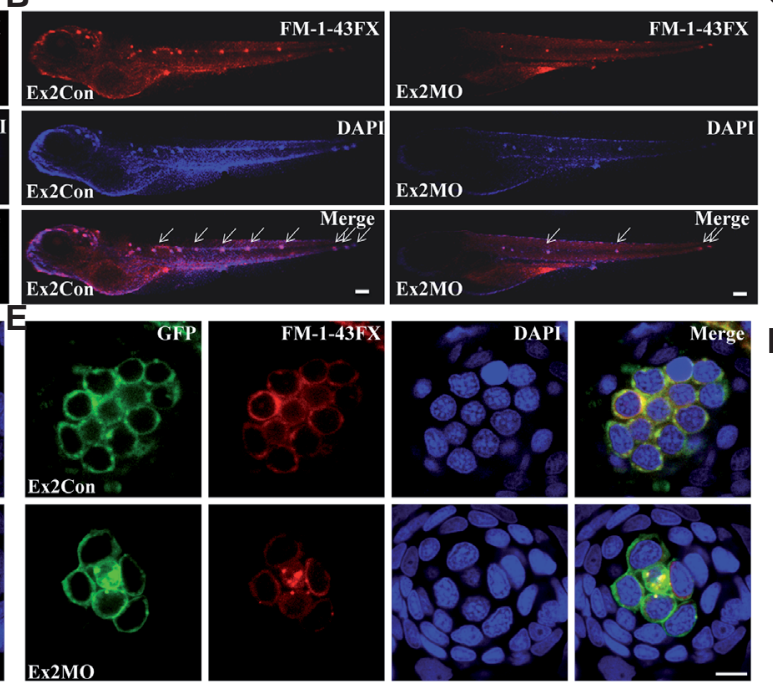

C

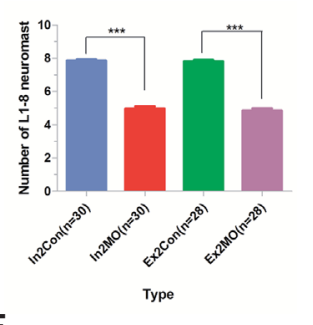

$F$

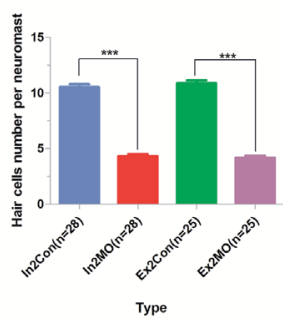

Fig. 4. Down-regulation of msrb3. L1-8 neuromasts were decreased and disordered and hair cells were reduced. (A,B; D,E) Hair cells in lateral line neuromasts stained with FM-1-43FX. (A,B) In2MO and Ex2MO morphants had fewer and more disordered primary neuromasts than controls. Scale bars: $150 \mu \mathrm{m}$. (D,E) Msrb3 morphants had fewer hair cells per neuromast than controls. Scale bars: 5 um. (C) Statistical analysis of the L1-8 neuromasts in mismatch controls and msrb3 morphants, " $n$ " represents fish number. (F) Statistical analysis of hair cells per neuromast in mismatch controls and msrb3 morphants, " $n$ " represents neuromasts number. Error bars are s.d. ${ }^{* *} \mathrm{P}<0.0001$.

motility and together facilitate the otolith formation (Nayak et al., 2007, Colantonio et al., 2009). Generally, otoliths appeared at $22 \mathrm{hpf}$, and became prominent by the prim- 6 stage ( $25 \mathrm{hpf}$ ) in the otic vesicle, enlarging along as stereocilia acquired regular motility. The primordia of the semicircular canals formed at 60 hpf, separating vesicles into otolith-containing chambers. By then, otolith morphology was stable. Thus, $60 \mathrm{hpf}$ was selected as the end of otolith observation and statistical analysis.

An autosomal recessive non-syndromic sensorineural hearing loss has been reported to be related to a homozygous single nucleotide conversion (265T>G) of MSRB3 in the six DFNB74 families (Ahmed et al., 2011). There are seven transcripts of msrb3 in zebrafish, one of which has no protein product (http:// www.ensembl.org). Two splicing morpholinos were designed to down-regulate the other six msrb3 transcripts simultaneously. In our hands, down-regulation of msrb3 in zebrafish contributed to progressive degeneration of stereocilia, followed by apoptotic hair cells, resulting in profound deafness in msrb3 morphants. These phenotypes are highly consistent with data from Msrb3 - mice. Thus, msrb3 plays an important role in hair cell integrity
A

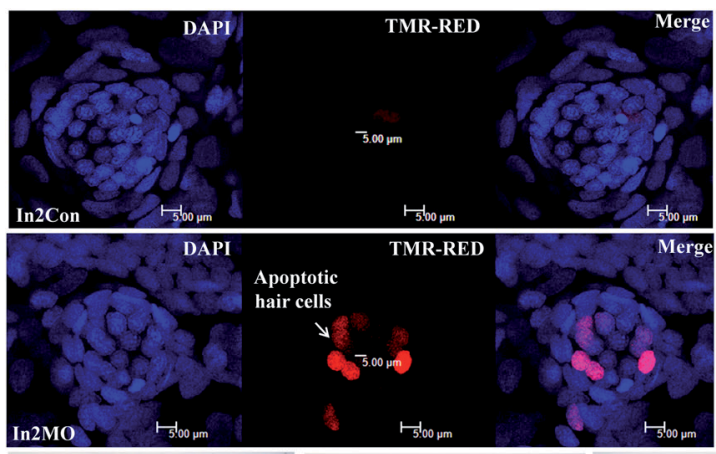

D

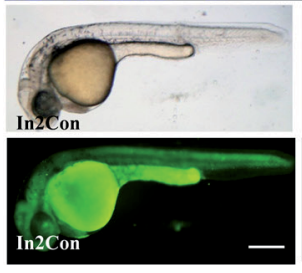

B
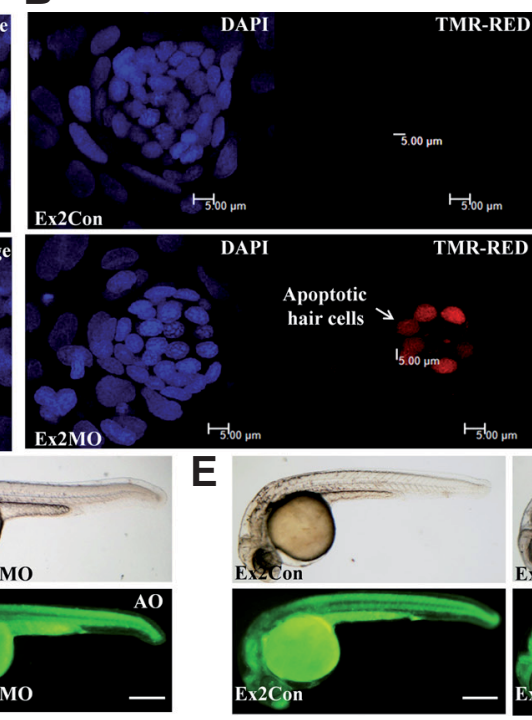

E

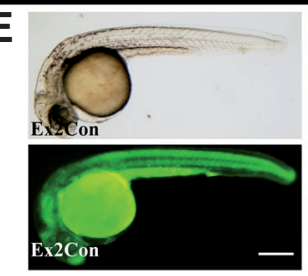

C

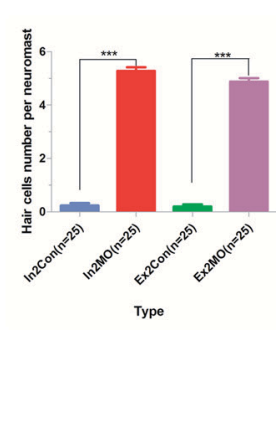

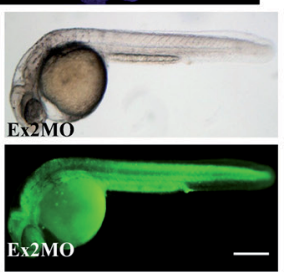

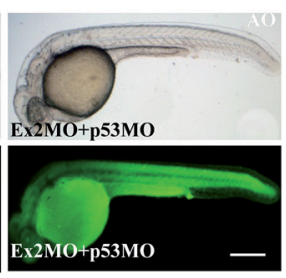

Fig. 5. Msrb3 morphant apoptotic hair cells. (A,B) TUNEL assay data. In 3 dpf larvae, msrb3 morphants had more hair cell apoptosis than mismatch controls. Scale bars, $5 \mu \mathrm{m}$. (C) Statistical analysis of apoptotic hair cells per neuromast in controls and msrb3 morphants, " $n$ " represents neuromasts number. Error bars are s.d. ${ }^{* *} \mathrm{P}<0.0001$. (D,E) Zebrafish embryos injected with msrb3 morpholinos (In2MO, Ex2MO) or co-injected with msrb3 morpholinos and p53MO-AO staining to detect whole larval apoptosis signal at 24 hpf. There was no difference between msrb3 morphants and p53MO co-injected larvae. The p53 off-target effect was ruled out. Scale bars, $200 \mu \mathrm{m}$. 
cells, possibly accounting for the pathogenesis behind hearing loss caused by an MSRB3 deficiency.

MSRB3 is widely expressed in mice and zebrafish. Previous reports indicate that no other disease is caused by this deafnessrelated mutation in humans (Ahmed et al., 2011). However, some phenotypes not related to hearing were observed in zebrafish morphants. These were characterized by disorganized somites, hydrocephaly, and pericardial effusion. It also is necessary to confirm whether other organs are affected at later stages of development.

The methionine sulfoxide reductase family (Msr) contains both methionine-S- sulfoxide reductase (MsrA) and methionine$R$-sulfoxide reductase (MsrB). These compounds play important roles in reducing methionine sulfoxide to methionine (Kim and Gladyshev, 2004, Weissbach et al., 2005) which can repair proteins damaged by oxidative stress as well as regulate the lifespans of several organisms (Lee et al., 2009). Ahmed reported that MSRB3 isoforms targeted to mitochondria were essential to hearing and this group concluded that loss of function of msrb3 led to progressive cilia damage, followed by apoptosis of hair cells, which caused profound deafness in msrb3 morphants. Furthermore, these morphants similar to phenotypes observed in

A

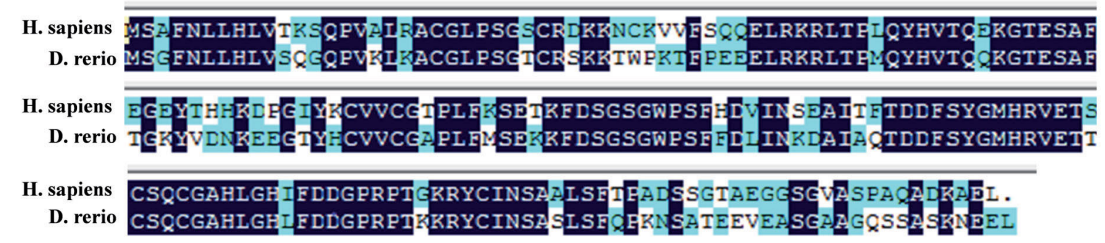

B

h-M3A
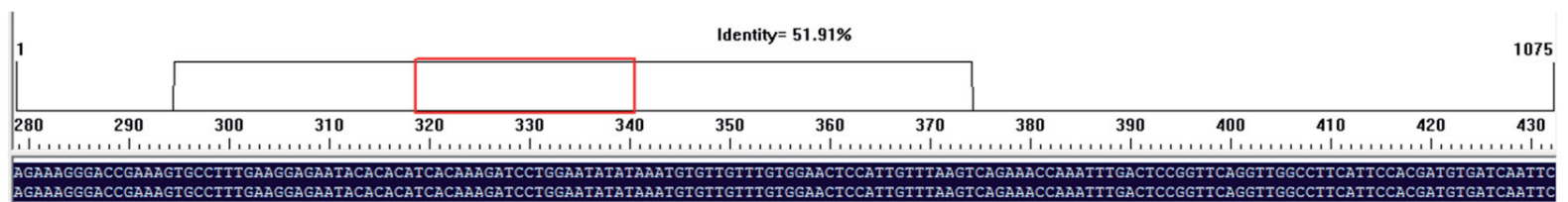
AgaAAGGGACCGAAGTGCCTTTGAAGGAGATACACACATCACAAAGATCCTGGAATATATAAATGTGTTGTTTGTGGAACTCCATTGTTTAAGTCAGAAACCAAATTTGACTCCGGTTCAGGTTGCCCTTCATTCCACGATGTGATCAATTC

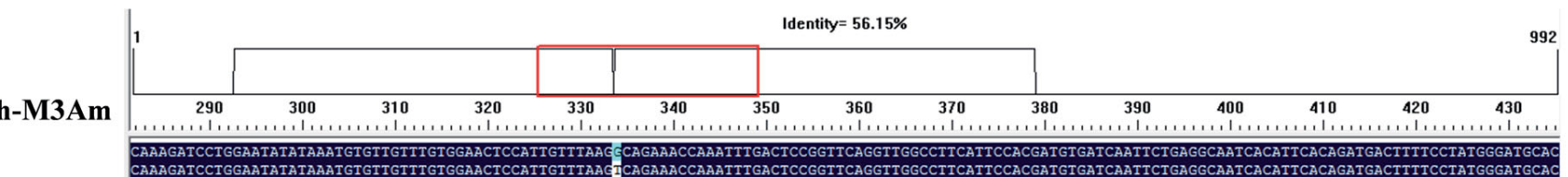

C

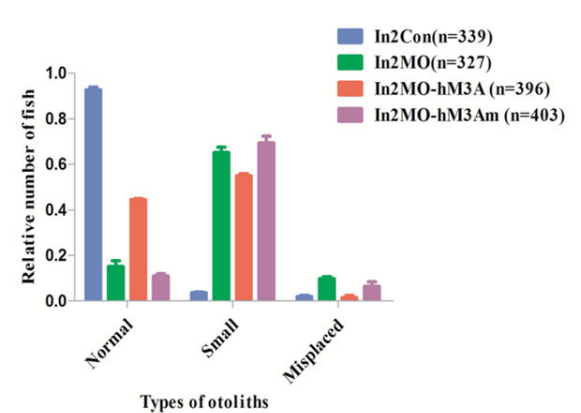

D

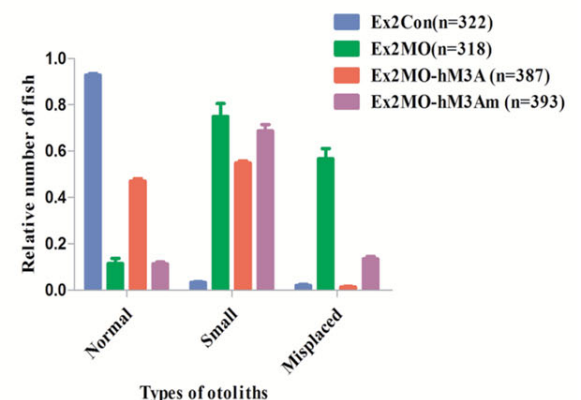

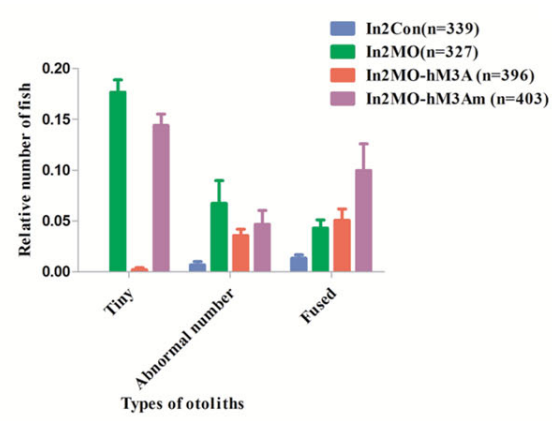

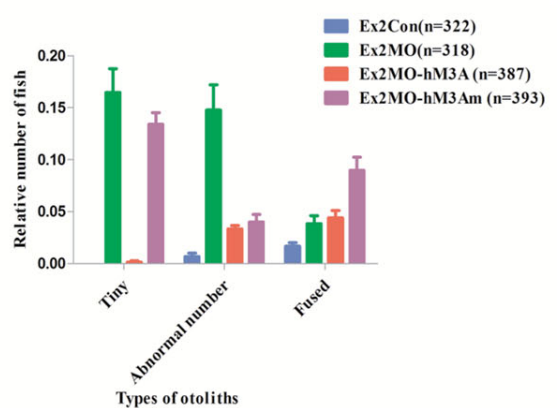

E

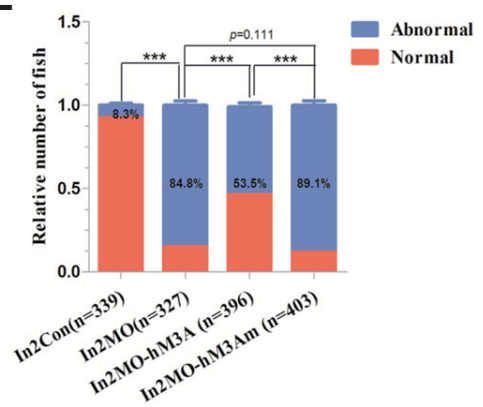

F

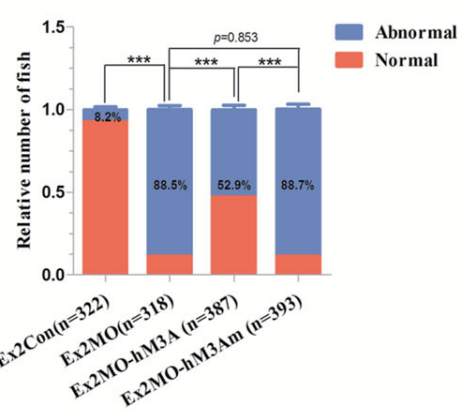

Fig. 6. MSRB3 comparisons. (A) Amino acid sequence comparison of MSRB3A between Homo sapiens and Danio rerio (68.28\% homology). (B) Human MSRB3A and MSRB3A mutants were obtained and transcribed into mRNA. (C,D) Overexpression of human MSRB3A mRNA rescued otic defects in morphants, but human MSRB3A mutant did not. Error bars are s.d. (E,F) Statistical analysis of otolith abnormality in different types of larvae. Human MSRB3A mRNA but not mutant MSRB3A mRNA rescued otic developmental defects. Error bars are s.d. ${ }^{* * * P<0.0001 .}$ 
Fig. 7. Msrb3 morphants are profoundly deaf. $(\mathbf{A}, \mathbf{C})$ Examples of C-shaped startle responses of different larval types after sound stimuli $(500 \mathrm{~Hz} ; 10 \mathrm{~ms})$. The escape response of control larvae was initiated 5-13 $\mathrm{ms}$ after the sound stimulation. Abnormal swimming behavior of msrb3 morphants indicated a defective balance system. Some morphants had no response to voice stimulation. After co-injection with human MSRB3A mRNA (hM3A), In2MO and Ex2MO zebrafish regained some hearing. (B,D) Average C-startle response probability. For each group, 30 larvae were tested. ${ }^{* *} \mathrm{P}<0.0001$.
A
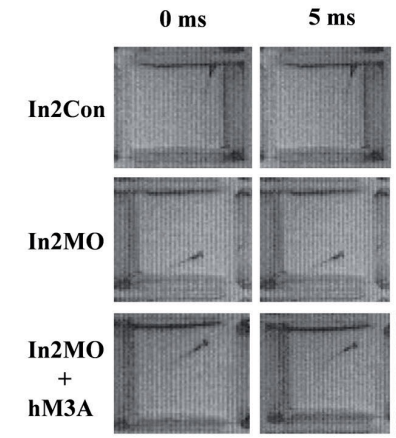

C
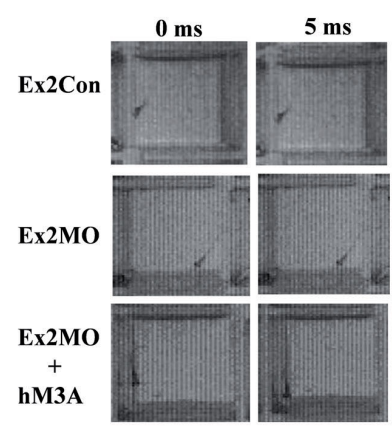
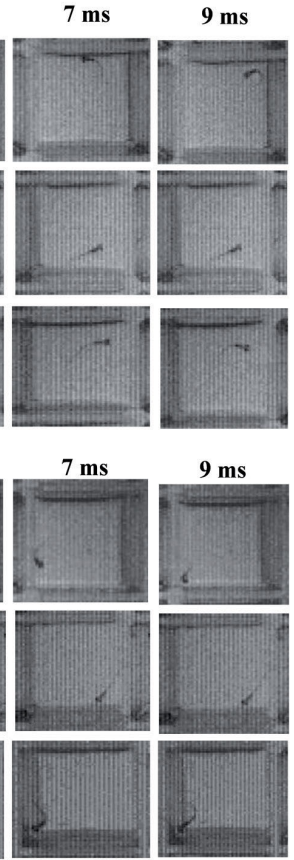
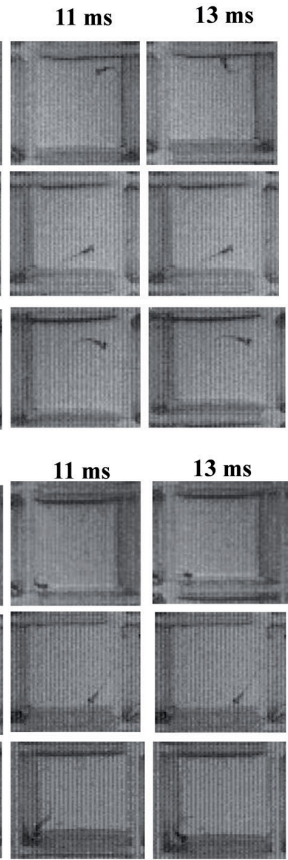

B

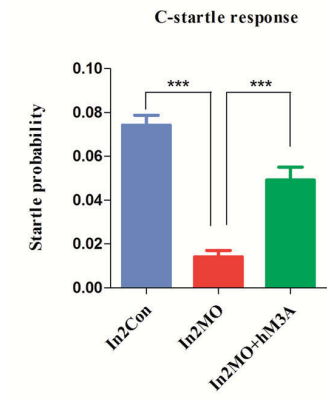

D

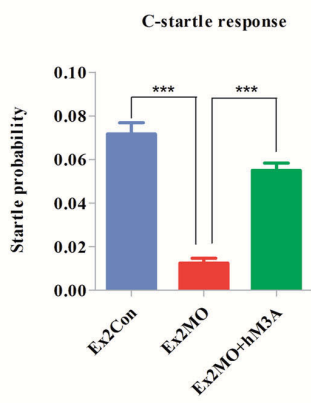

the DFNB74 patients (Ahmed et al., 2011). In summary, we have offered a foundation for studying the pathogenesis of DFNB74 deafness, and we have established that the msrb3 morphant is a suitable animal model for further research into the mechanisms underlying human DFNB74 hearing loss.

\section{Materials and Methods}

\section{Zebrafish lines}

The zebrafish $A B$ line was used and these were raised according to the standard protocol described in The Zebrafish Book. Transgenic pou3f4GFP zebrafish embryos were provided by Dr. Huawei Li. Embryos were kept at $28.5^{\circ} \mathrm{C}$ and $0.003 \%$ 1-phenyl-2-thiourea (PTU, Sigma) was used to suppress pigmentation (Karlsson et al., 2001). Developmental stages were judged by hpf and number of somites (S). Experimental procedures and animal use and care protocols were approved by the Fudan University Animal Ethics Committee.

\section{Morpholino antisense oligonucleotides and microinjection}

Two morpholino antisense oligonucleotides were designed to prevent correct splicing of msrb3in zebrafish. One morpholino (+intron2MO, In2MO) targeted the splice junction between intron2 and exon3, causing intron2 to be retained. The other one ( $\triangle$ exon2MO, Ex2MO) targeted the splice junction between intron 1 and exon2, causing exon2 to be removed. Mismatch controls allowed researchers to interpret morpholino experiments correctly and completely (Eisen and Smith, 2008). In2MO: 5'-TGTCAAACCGTGTGACACACCTCTC-3'; In2Con: 5'-TGTgAAAgCcT GTCACAgACCTCTC-3'; Ex2MO:5'-CACGTTCCTAATGGAAATACAAGCA-3'; Ex2Con:5'-CACcTTgCTAATcGAAATAgAAcCA-3'. All sequences were obtained from Gene Tools Website (http://www.gene-tools.com/Oligo_Design). After synthesis, morpholinos were diluted with RNase-free water (Takara).

Morpholinos were injected into embryos at the one-cell stage (Xu, 1999). with either 8, 4, 2, or 1 of one type splicing morpholino (In2MO, Ex2MO) or with $4 \mathrm{ng}$ mismatch control morpholinos (In2Con, Ex2Con).

Human MSRB3A and MSRB3A-265T>G were amplified through reverse transcription PCR (RT-PCR) and verified by sequencing. DNA generated by PCR can be transcribed directly from the PCR provided it contains a T7 RNA polymerase promoter upstream of the sequence to be transcribed.
Then MSRB3A and MSRB3A-265T>G mRNA were synthesized in vitro according to the instructions provided with the MMESSAGE MMACHINE ${ }^{\circledR}$ T7 Ultra Kit (Ambion).

\section{$R T-P C R$}

Reverse transcription PCR was performed as described previously (Zhao et al., 2010). Primer pairs used in reverse transcription PCR to detect the knockdown efficiency of In2MO are 5'-GACATGGCCTAAAACGTTCC-3' (forward in exon 2) and 5'-AAGAGGTGCAC CGCAAAC-3' (reverse in exon3) or 5'-GCTCATTTTGG TGGTACTTCG-3' (reverse in intron2). The two primer pairs yielded $179 \mathrm{bp}$ (normal splicing) or $299 \mathrm{bp}$ (intron 2 retained). If the mRNA of $m s r b 3$ was correctly spliced, the primer combination produces a $179 \mathrm{bp}$ product. If intron2 is retained, a $299 \mathrm{bp}$ results. Primers used to assess the efficiency of Ex2MO down-regulation were $5^{\prime}$-CGTGCCGAAGTAAGAAGACA-3' (forward in exon 2) and 5'-AAGAGGTGCA CCGCAAAC-3' (reverse in exon 3) and these primers produced a $163 \mathrm{bp}$ product. If exon 2 had been removed, less of this product would be evident.

\section{Whole-mount in situ hybridization (WISH)}

Msrb3 complementary DNA of zebrafish was subcloned into the vector pGEM 8 -T by PCR amplification with 5'-CGCTGTTTCTGTT CACCC-3' (forward) and 5'-TCCGACCAATGTTGC TAA-3' (reverse). pGEM-msrb3 was linearized using Sall and the antisense digoxigenin-UTP-labeled fulllength riboprobe was transcribed using T7 RNA polymerase (Promega). Zebrafish embryos were collected at different stages of development, washed three times with PBST in DEPC, and fixed in $0.5 \mathrm{ml} 4 \%$ paraformaldehyde for $5 \mathrm{~min}$ at room temperature. Then paraformaldehyde was removed and samples were fixed in another $0.5 \mathrm{ml}$ paraformaldehyde for $12-16 \mathrm{~h}$ at 4 ${ }^{\circ} \mathrm{C}$ before WISH which was performed primarily as described previously (Chen and Fishman, 1996, Tian et al., 2009, Le Guellec et al., 2004). Antidigoxigenin antibody (Roche) was used to detect msrb3 mRNA signals.

\section{FM-1-43FX and phalloidin staining}

Hair cells in lateral line neuromasts were labeled by immersing $5 \mathrm{dpf}$ larvae in a solution of FM1-43FX (Invitrogen) in breeding water for 1-2 min at room temperature, and then the water was changed several times until clear. Zebrafish were immobilized in $1 \%$ low melting point agarose gel and labeled hair cells were imaged under a confocal microscope. Cilia in the inner ears of $5 \mathrm{dpf}$ zebrafish were marked with $2.5 \mathrm{mg} / \mathrm{ml}$ fluorescein 
isothiocyanate (FITC)-labeled phalloidin (Sigma) in PBS for $2 \mathrm{~h}$ in the dark after immersion in $4 \%$ paraformaldehyde and then incubated overnight at $4{ }^{\circ} \mathrm{C}$ in $2 \%$ Triton $\mathrm{X}-100$ (Sigma) in PBS. Then embryos were washed several times in PBS over the course of $2 \mathrm{~h}$ and viewed with a confocal microscope (Leger and Brand, 2002).

\section{Scanning electron microscopy (SEM)}

All SEM images were taken of larvae at $5 \mathrm{dpf}$. This stage is early enough to observe many developing hair bundles, but late enough to adequately preserve larvae. For our sequential analysis individual larvae were anesthetized with $0.03 \%$ MESAB and pinned onto a Sylgard-filled chamber. After imaging, the cupula surrounding neuromasts was removed by incubating larvae in a high dose of MESAB $(0.12 \%)$ for $25 \mathrm{~s}$. Specimens were then fixed in $2.5 \%$ glutaraldehyde, $2 \mathrm{mM} \mathrm{CaCl}_{2}$ in $0.1 \mathrm{M}$ cacodylate buffer for $2 \mathrm{hrs}$ at room temperature. Samples were washed and post-fixed in 80 $\mathrm{mM}$ cacodylate buffer and $4 \mathrm{mM} \mathrm{CaCl}_{2}$ for $10 \mathrm{~min}$ on ice. Embryos were washed five times with water and then dehydrated in steps from $50 \%$ to $100 \%$ ethanol at room temperature. Larvae were then critical point dried and mounted on carbon covered aluminum stubs. The head and tail tip of each larvae were painted with silver to minimize charging. Lastly samples were sputter coated with gold-palladium. A FEI Sirion XL30 scanning electron microscope was used to acquire images.

\section{Apoptosis detection}

TUNEL assay was detected with TMR-RED in situ cell death detection kit (Roche). Then, 3 dpf embryos were dechorionated and fixed in 4\% PFA paraformaldehyde overnight at $4{ }^{\circ} \mathrm{C}$, immersed in methanol for $1 \mathrm{~h}$ at room temperature, and washed three times with PBST. Samples were incubated in acetone at $-20{ }^{\circ} \mathrm{C}$ for $10 \mathrm{~min}$, permeabilized with $0.1 \%$ sodium citrate and $0.1 \%$ TritonX-100 for $15 \mathrm{~min}$ at room temperature, and washed twice in PBST buffer. Samples were then incubated with the reaction mixture $(5 \mu \mathrm{l}$ of enzyme solution $+45 \mu$ l label solution) for $1 \mathrm{~h}$ in the dark at $37^{\circ} \mathrm{C}$. The reaction was stopped by washing three times with PBST. The fluorescent signal was visualized and imaged using a Zeiss LSM510 microscope.

\section{Acridine orange staining}

Acridine orange $(\mathrm{AO})$ staining was used to detect apoptotic signals in whole zebrafish larvae to rule out p53 off-target effects (Abrams et al., 1993). Larvae at $24 \mathrm{hpf}$ were immersed in $2 \mu \mathrm{g} / \mathrm{ml} \mathrm{AO}$ in the dark in breeding water for $1 \mathrm{~h}$ at room temperature. Then larvae were washed three times with breeding water for 10 min each. Images were obtained with DIC microscopy.

\section{Startle response tests}

The C-shaped startle response using near-field pure tone stimulation with sound intensity was used to test larval hearing (Bang et al., 2002). This experiment was tested in 96-well plastic plates, and recorded with a high-speed camera (Redlake, MotionScope M3, 1,000 fps) under infrared light illumination. Pure tone stimulations $(10 \mathrm{~ms}, 500 \mathrm{~Hz})$ at two different intensities were given through a plastic board mounted on a voice box $(\mathrm{HiVi}$, D1080MKII). Each larva was tested 13-15 times and the relative number of C-startle responses was calculated for each larva. The probability of the C-startle response for a larval group was the average percentage of C-startle reflexes (Han et al., 2011).

\section{Statistical analysis}

Statistical analysis was performed using two-way ANOVA with multiple comparisons. Significance was set at $P<0.05$ and extreme significance was set at $P<0.001$.

\section{Acknowledgments and funding}

This study was supported by the National Basic Research Program of China (2011CB504500), Foundation of Ministry of Health (201202005), Shanghai Scientific and Technology Projects (2013ZYJB0015 and 14DJ1400103).

\section{References}

ABRAMS, J. M., WHITE, K., FESSLER, L. I. and STELLER, H. (1993). Programmed cell death during Drosophila embryogenesis. Development 117: 29-43.

AHMED, Z. M., YOUSAF, R., LEE, B. C., KHAN, S. N., LEE, S., LEE, K., HUSNAIN, T., REHMAN, A. U., BONNEUX, S., ANSAR, M., AHMAD, W., LEAL, S. M., GLADYSHEV, V. N., BELYANTSEVA, I. A., VAN CAMP, G., RIAZUDDIN, S. and FRIEDMAN, T. B. (2011). Functional null mutations of MSRB3 encoding methionine sulfoxide reductase are associated with human deafness DFNB74. Am J Hum Genet 88: 19-29.

BANG, P. I., SEWELL, W. F. and MALICKI, J. J. (2001). Morphology and cell type heterogeneities of the inner ear epithelia in adult and juvenile zebrafish (Danio rerio). J Comp Neurol 438: 173-190.

BANG, P. I., YELICK, P. C., MALICKI, J. J. and SEWELL, W. F. (2002). High-throughput behavioral screening method for detecting auditory response defects in zebrafish. $J$ Neurosci Methods 118: 177-187.

BEVER, M. M. and FEKETE, D. M. (2002). Atlas of the developing inner ear in zebrafish. Dev Dyn 223: 536-543.

BLANCHARD, M., THIERRY, B., MARLIN, S. and DENOYELLE, F. (2012). [Genetic aspects of congenital sensorineural hearing loss]. Arch Pediatr 19: 886-889.

BORCK, G., URREHMAN, A., LEE, K., POGODA, H. M., KAKAR, N., VONAMELN, S., GRILLET, N., HILDEBRAND, M. S., AHMED, Z. M., NURNBERG, G., ANSAR, M., BASIT, S., JAVED, Q., MORELL, R. J., NASREEN, N., SHEARER, A. E., AHMAD, A., KAHRIZI, K., SHAIKH, R. S., ALI, R. A., KHAN, S. N., GOEBEL, I., MEYER, N. C., KIMBERLING, W. J., WEBSTER, J. A., STEPHAN, D. A., SCHILLER, M. R., BAHLO, M., NAJMABADI, H., GILLESPIE, P. G., NURNBERG, P., WOLLNIK, B., RIAZUDDIN, S., SMITH, R. J., AHMAD, W., MULLER, U., HAMMERSCHMIDT, M., FRIEDMAN, T. B., LEAL, S. M., AHMAD, J. and KUBISCH, C. (2011). Lossof-function mutations of ILDR1 cause autosomal-recessive hearing impairment DFNB42. Am J Hum Genet 88: 127-137.

CHEN, J. N. and FISHMAN, M. C. (1996). Zebrafish tinman homolog demarcates the heart field and initiates myocardial differentiation. Development 122: 3809-3816.

CHENG, J., ZHU, Y., HE, S., LU, Y., CHEN, J., HAN, B., PETRILLO, M., WRZESZCZYNSKI, K. O., YANG, S., DAI, P., ZHAI, S., HAN, D., ZHANG, M. Q., LI, W., LIU, X., LI, H., CHEN, Z. Y. and YUAN, H. (2011). Functional mutation of SMAC/ DIABLO, encoding a mitochondrial proapoptotic protein, causes human progressive hearing loss DFNA64. Am J Hum Genet 89: 56-66.

COLANTONIO, J. R., VERMOT, J., WU, D., LANGENBACHER, A. D., FRASER, S., CHEN, J. N. and HILL, K. L. (2009). The dynein regulatory complex is required for ciliary motility and otolith biogenesis in the inner ear. Nature 457: 205-209.

DROR, A. A. and AVRAHAM, K. B. (2010). Hearing impairment: a panoply of genes and functions. Neuron 68: 293-308.

EISEN, J. S. and SMITH, J. C. (2008). Controlling morpholino experiments: don't stop making antisense. Development 135: 1735-1743.

EKKER, S. C. and LARSON, J. D. (2001). Morphant technology in model developmental systems. Genesis 30: 89-93.

FRIEDMAN, T. B. and GRIFFITH, A. J. (2003). Human nonsyndromic sensorineural deafness. Annu Rev Genomics Hum Genet 4: 341-402.

FROLENKOV, G. I., BELYANTSEVA, I. A., FRIEDMAN, T. B. and GRIFFITH, A. J. (2004). Genetic insights into the morphogenesis of inner ear hair cells. Nat Rev Genet 5: 489-498.

GERETY, S. S. and WILKINSON, D. G. (2011). Morpholino artifacts provide pitfalls and reveal a novel role for pro-apoptotic genes in hindbrain boundary development. Dev Biol 350: 279-289.

GHYSEN, A. (2003). The origin and evolution of the nervous system. Int J Dev Biol 47: $555-562$

GILLESPIE, P. G. and MULLER, U. (2009). Mechanotransduction by hair cells: models, molecules, and mechanisms. Cell 139: 33-44.

GLEASON, M. R., NAGIEL, A., JAMET, S., VOLOGODSKAIA, M., LOPEZ-SCHIER, H. and HUDSPETH, A. J. (2009). The transmembrane inner ear (Tmie) protein is essential for normal hearing and balance in the zebrafish. Proc Natl Acad Sci USA 106: 21347-21352.

HADDON, C. and LEWIS, J. (1996). Early ear development in the embryo of the zebrafish, Danio rerio. J Comp Neurol 365: 113-128.

HAN, Y., MU, Y., LI, X., XU, P., TONG, J., LIU, Z., MA, T., ZENG, G., YANG, S., DU, 
J. and MENG, A. (2011). Grhl2 deficiency impairs otic development and hearing ability in a zebrafish model of the progressive dominant hearing loss DFNA28. Hum Mol Genet 20: 3213-3226.

HE, Y., YU, H., SUN, S., WANG, Y., LIU, I., CHEN, Z. and LI, H. (2013). Trans2-phenylcyclopropylamine regulates zebrafish lateral line neuromast development mediated by depression of LSD1 activity. Int J Dev Biol 57: 365-373.

HILGERT, N., SMITH, R. J. and VAN CAMP, G. (2009). Forty-six genes causing nonsyndromic hearing impairment: which ones should be analyzed in DNA diagnostics? Mutat Res 681: 189-196.

KARLSSON, J., VON HOFSTEN, J. and OLSSON, P. E. (2001). Generating transparent zebrafish: a refined method to improve detection of gene expression during embryonic development. Mar Biotechnol (NY) 3: 522-527.

KELLEY, M. W. (2007). Cellular commitment and differentiation in the organ of Corti. Int J Dev Biol 51: 571-583.

KIM, H. Y. and GLADYSHEV, V. N. (2004). Methionine sulfoxide reduction in mammals: characterization of methionine-R-sulfoxide reductases. Mol Biol Cell15: 1055-1064.

KIMMEL, C. B., BALLARD, W. W., KIMMEL, S. R., ULLMANN, B. and SCHILLING, T. F. (1995). Stages of embryonic development of the zebrafish. Dev Dyn203:253-310.

KWON, T. J., CHO, H. J., KIM, U. K., LEE, E., OH, S. K., BOK, J., BAE, Y. C., YI, J. K., LEE, J. W., RYOO, Z. Y., LEE, S. H., LEE, K. Y. and KIM, H. Y. (2014). Methionine sulfoxide reductase $B 3$ deficiency causes hearing loss due to stereocilia degeneration and apoptotic cell death in cochlear hair cells. Hum Mol Genet23: 1591-1601.

LE GUELLEC, D., MORVAN-DUBOIS, G. and SIRE, J. Y. (2004). Skin development in bony fish with particular emphasis on collagen deposition in the dermis of the zebrafish (Danio rerio). Int J Dev Biol 48: 217-231.

LEE, B. C., DIKIY, A., KIM, H. Y. and GLADYSHEV, V. N. (2009). Functions and evolution of selenoprotein methionine sulfoxide reductases. Biochim Biophys Acta 1790: 1471-1477.

LEGER, S. and BRAND, M. (2002). Fgf8 and Fgf3 are required for zebrafish ear placode induction, maintenance and inner ear patterning. Mech Dev 119: 91-108.

MA, E. Y., RUBEL, E. W. and RAIBLE, D. W. (2008). Notch signaling regulates the extent of hair cell regeneration in the zebrafish lateral line. J Neurosci28: 2261-2273.

NAGIEL, A., ANDOR-ARDO, D. and HUDSPETH, A. J. (2008). Specificity of afferent synapses onto plane-polarized hair cells in the posterior lateral line of the zebrafish. J Neurosci 28: 8442-8453.

NAYAK, G. D., RATNAYAKA, H. S., GOODYEAR, R. J. and RICHARDSON, G. P. (2007). Development of the hair bundle and mechanotransduction. Int J Dev Biol 51: 597-608.
ROBU, M. E., LARSON, J. D., NASEVICIUS, A., BEIRAGHI, S., BRENNER, C., FARBER, S. A. and EKKER, S. C. (2007). p53 activation by knockdown technologies. PLoS Genet 3: e78.

TIAN, T., ZHAO, L., ZHAO, X., ZHANG, M. and MENG, A. (2009). A zebrafish gene trap line expresses GFP recapturing expression pattern of foxj1b. J Genet Genomics 36: 581-589.

USAMI, S., ABE, S., SHINKAWA, H. and KIMBERLING, W. J. (1998). Sensorineural hearing loss caused by mitochondrial DNA mutations: special reference to the A1555G mutation. J Commun Disord 31: 423-434; quiz 434-425.

WATERMAN, R. E. and BELL, D. H. (1984). Epithelial fusion during early semicircular canal formation in the embryonic zebrafish, Brachydanio rerio. Anat Rec 210: 101-114.

WEISSBACH, H., ETIENNE, F., HOSHI, T., HEINEMANN, S. H., LOWTHER, W. T., MATTHEWS, B., ST JOHN, G., NATHAN, C. and BROT, N. (2002). Peptide methionine sulfoxide reductase: structure, mechanism of action, and biological function. Arch Biochem Biophys 397: 172-178.

WEISSBACH, H., RESNICK, L. and BROT, N. (2005). Methionine sulfoxide reductases: history and cellular role in protecting against oxidative damage. Biochim Biophys Acta 1703: 203-212.

WHITFIELD, T. T. (2002). Zebrafish as a model for hearing and deafness. J Neurobiol 53: 157-171.

WU, G. F., HOU, Y. L., HOU, W. R., SONG, Y. and ZHANG, T. (2010). Giant panda ribosomal protein $\mathrm{S} 14$ : cDNA, genomic sequence cloning, sequence analysis, and overexpression. Genet Mol Res 9: 2004-2015.

XU, Q. (1999). Microinjection into zebrafish embryos. Methods Mol Biol 127: 125-132.

ZHAO, X., ZHAO, L., TIAN, T., ZHANG, Y., TONG, J., ZHENG, X. and MENG, A. (2010). Interruption of cenph causes mitotic failure and embryonic death, and its haploinsufficiency suppresses cancer in zebrafish. JBiol Chem285: 27924-27934.

\section{Web references}

http://hereditaryhearingloss.org/main.aspx?c=. HHH\&n=86307

http://www.gene-tools.com/Oligo_Design

http://zfin.org/zf_info/anatomy/dict/current.html

http://www.ensembl.org

http://www.ncbi.nlm.nih.gov/unigene?term=msrb3 


\section{Further Related Reading, published previously in the Int. J. Dev. Biol.}

Trans-2-phenylcyclopropylamine regulates zebrafish lateral line neuromast development mediated by depression of LSD1 activity Yingzi He, Huiqian Yu, Shan Sun, Yunfeng Wang, Liman Liu, Zhengyi Chenand Huawei Li Int. J. Dev. Biol. (2013) 57: 365-373

http://dx.doi.org/10.1387/ijdb.120227hl

Calnexin is required for zebrafish posterior lateral line development

I-Chen Hung, Bor-Wei Cherng, Wen-Ming Hsu and Shyh-Jye Lee

Int. J. Dev. Biol. (2013) 57: 427-438

http://dx.doi.org/10.1387/ijdb.120166sl

Patterning the nervous system through development and evolution

Alain Ghysen, Christine Dambly-Chaudière and David W. Raible

Int. J. Dev. Biol. (2010) 54: S1-S14

http://dx.doi.org/10.1387/ijdb.103182ag

Development of the posterior lateral line system in Thunnus thynnus, the atlantic blue-fin tuna, and in its close relative Sarda sarda Alain Ghysen, Kevin Schuster, Denis Coves, Fernando de la Gandara, Nikos Papandroulakis and Aurelio Ortega

Int. J. Dev. Biol. (2010) 54: 1317-1322

http://dx.doi.org/10.1387/ijdb.103102ag

Hair cell regeneration in the avian auditory epithelium

Jennifer S. Stone and Douglas A. Cotanche

Int. J. Dev. Biol. (2007) 51: 633-647

http://dx.doi.org/10.1387/ijdb.072408js

Development of the hair bundle and mechanotransduction

Gowri D. Nayak, Helen S.K. Ratnayaka, Richard J. Goodyear and Guy P. Richardson Int. J. Dev. Biol. (2007) 51: 597-608

http://dx.doi.org/10.1387/ijdb.072392gn

Cellular commitment and differentiation in the organ of Corti

Matthew W. Kelley

Int. J. Dev. Biol. (2007) 51: 571-583

http://dx.doi.org/10.1387/ijdb.072388mk

5 yr ISI Impact Factor $(2013)=2.879$
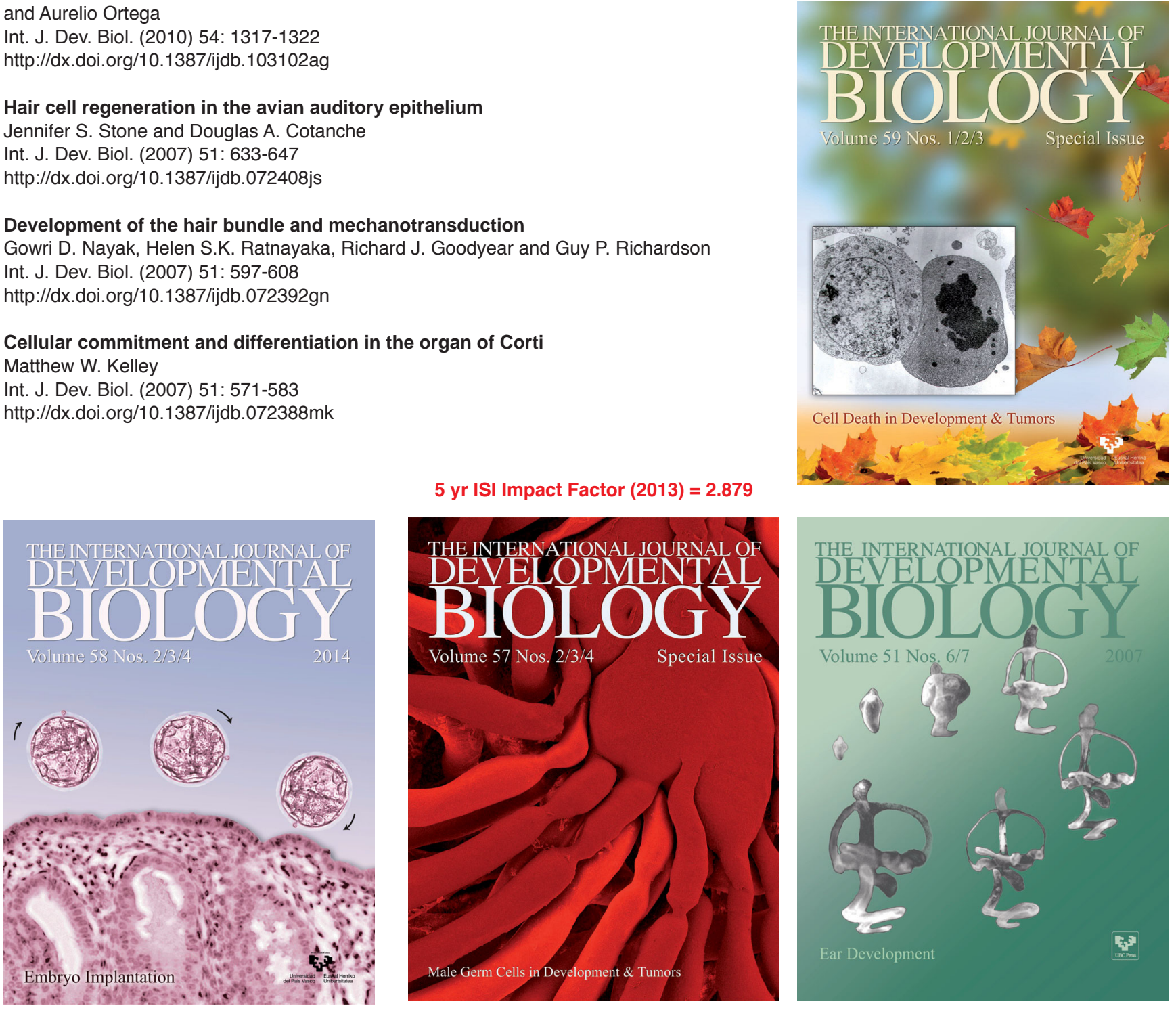